\title{
SISTEMÁTICA E TAFONOMIA DE UMA FÁUNULA DE CRUSTÁCEOS DECÁPODES DA FORMAÇÃO MARIA FARINHA (PALEOCENO), ESTADO DE PERNAMBUCO, BRASIL
}

\author{
VLADIMIR DE ARAÚJO TÁVORA \& MARIA CAROLINA DA CRUZ MIRANDA \\ Depto. de Geologia, CG, UFPa, Cx. P. 1611, 66075-110, Belém, PA, Brasil. \\ vtavora@orm.com.br,carol@ufpa.br
}

\begin{abstract}
RESUMO - O estudo de 52 exemplares de crustáceos decápodes da Formação Maria Farinha, oriundos da pedreira Poty, município de Paulista, Estado de Pernambuco, revelou a ocorrência das espécies Necrocarcinus sp. e Costacopluma nordestina Feldmann \& Martins-Neto. A associação de decápodes é caracterizada como restos alóquemes em rochas carbonáticas. Apresentam-se, na grande maioria, desarticulados e fragmentados, indicando elevada energia no ambiente deposicional durante o evento de soterramento. Cerca de $89 \%$ da tafocenose é constituída por tórax isolados, quelípodes articulados com o tórax e dátilos isolados, definindo a posição de soterramento normal. Os $11 \%$ restantes ocorrem como quelípodes articulados com o tórax e esterno, recurvados para cima, caracterizando a posição de soterramento de escape. As feições preservacionais indicam que o ambiente deposicional era extremamente variável em termos de energia, intercalando períodos mais agitados, que fragmentavam os restos de organismos já mortos, com períodos mais calmos, onde os restos eram acumulados, depositados e sepultados. A preservação em posição de escape indica que o soterramento aconteceu quando o ambiente passava rapidamente de um período mais calmo para outro mais agitado, surpreendendo, assim, alguns indivíduos da biocenose. Isso indica tratar-se de um ambiente costeiro, sujeito a oscilações do nível do mar, hipótese esta corroborada pelo ambiente de vida de braquiúres atuais das famílias Goneplacidae e Ocypodidae, típicos de mangue.
\end{abstract}

Palavras-chave: crustáceos decápodes, sistemática, tafonomia, Paleoceno, Formação Maria Farinha.

ABSTRACT - SYSTEMATIC AND TAPHONOMY OF A FAUNULE OF THE DECAPOD CRUSTACEANS OF THE MARIA FARINHA FORMATION (PALEOCENE), PERNAMBUCO STATE, BRAZIL. The study of 52 decapod crustacean specimens of the Maria Farinha Formation, collected at the Poty Quarry, district of Paulista, State of Pernambuco, revealed the occurrence of the Necrocarcinus sp. and Costacopluma nordestina Feldmann \& Martins-Neto. The fossiliferous association is characterized by allochem remains in carbonatic rocks. They occur mostly dislocated and fragmented, indicating high energy in the depositional environment during the burial event. About $89 \%$ of taphocoenosis is represented by isolated thorax (dominantly), chelipeds articulated with the thorax, and isolated dactylus, defining the normal burial position. The remaining $11 \%$ occurs as articulated chelipeds with the thorax and sternum, curved upwards, sugesting the escape position. The preservational features indicate that the deposicional environment was extremely variable in energy, intercalating high energy periods, in which dead organisms remains were fragmentated, with low energy periods, in which the remains were accumulated, deposited and buried. The preservation in escape position indicates that the burial happened during the quick changes between low and high energy periods, suggesting a coastal environment, under the sea level oscillations. This hypothesis is corroborated by taxa found in the environment here identified, corresponding to members of the Goneplacidae and Ocypodidae families, typical of swamps.

Key words: Decapod crustaceans, systematics, taphonomy, Paleocene, Maria Farinha Formation.

\section{INTRODUÇÃO}

Os crustáceos decápodes da Formação Maria Farinha foram estudados por Beurlen $(1959,1967)$, que citou a ocorrência dos gêneros Callianassa, Plagiolophus, Carinuca e Retrocypoda, além de apêndices de pagurídeos, ao longo da unidade litoestratigráfica, sem entretanto, descre- ver as diferentes espécies. Beurlen $(1959,1967)$ acrescentou que estes táxons correspondem aos atuais membros das famílias Goneplacidae e Ocypodidae, viventes no interior de sedimentos lodosos da zona litoral das marés, característicos de ambiente de mangue. Beurlen (1959) citou, ainda, a ocorrência de uma subespécie do gênero Ophthalmoplax, O. postumus pernambucana, definida por 
ele próprio. Entretanto, a proposição formal deste táxon nunca foi realizada, tendo sido citada apenas neste trabalho (nome nudum).

Pelo exposto, observa-se que o conhecimento acerca da paleocarcinofauna da Formação Maria Farinha é muito restrito. Em coletas recentes realizadas na pedreira Poty, município de Paulista, Estado de Pernambuco, por uma equipe de paleontólogos da Universidade do Estado do Rio de Janeiro e do Museu Nacional, foram coletados 43 exemplares, cedidos para este estudo. Também foram utilizados nesta pesquisa nove indivíduos sem numeração, todos do Departamento de Geologia da Universidade Federal de Pernambuco. O material estudado está catalogado na coleção paleontológica do Departamento de Geologia e Paleontologia do Museu Nacional do Rio de Janeiro, sob a numeração MN-7992-I a MN-8043-I,

O presente trabalho trata da caracterização sistemática e tafonômica dos crustáceos decápodes da Formação Maria Farinha. Para tanto, foram utilizados os 52 exemplares disponíveis, com seus respectivos dados de campo. Esta pesquisa insere-se em um contexto maior, que é o estudo das paleocarcinofaunas pós-paleozóicas brasileiras, iniciado com as formas miocênicas da Formação Pirabas (Távora, 2000; Távora, 2001; Távora \& Silva Junior, 2002; Távora et al., 2002).

\section{GEOLOGIA}

\section{A bacia Pernambuco-Paraíba e a Formação Maria Farinha}

A bacia Pernambuco-Paraíba localiza-se no nordeste do Brasil, na região costeira e margem continental dos estados da Paraíba e Pernambuco e na porção oriental do Rio Grande do Norte. Possui uma coluna sedimentar incompleta em relação às outras bacias marginais (Muniz, 1993), faltando os evaporitos da fase proto-oceânica e a espessa seção clástica da fase marinha franca, exibidos nas outras bacias da margem continental brasileira.

Estudos recentes na bacia Pernambuco-Paraíba resulta-

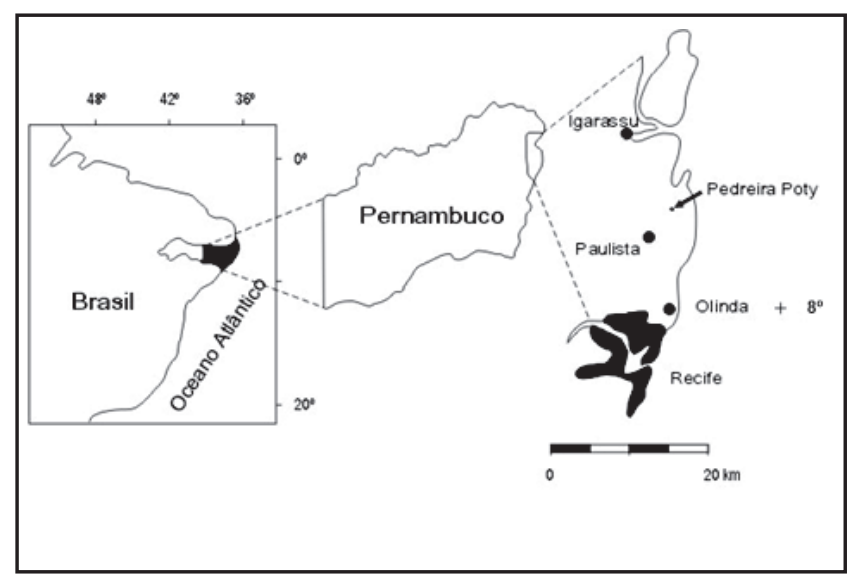

Figura 1. Localização da pedreira Poty (modificado de Stinnesbeck \& Keller, 1996).

Figure 1. Location of the Poty Quarry (modified from Stinnesbeck \& Keller, 1996). ram na definição do limite Cretáceo-Terciário com base em dados paleontológicos (Mabesoone et al., 1968; Albertão et al., 1993, 1994), além de análises geoquímicas, que mostraram uma anomalia de irídio significativa. Tal limite situa-se a cerca de $40 \mathrm{~cm}$ acima do contato litológico entre as formações Gramame e Maria Farinha na Jazida Poty e, portanto, incluído na Fomação Maria Farinha.

A Formação Maria Farinha possui uma grande variabilidade litológica, caracterizando-se por uma seqüência de calcários fossilíferos detríticos com estratificação plano paralela. O perfil consiste basicamente em duas seções. A inferior, de pequena espessura, constituída por um calcário litográfico, com fósseis relativamente raros, esparsamente distribuídos, sem acumulações locais. A segunda seção, mais espessa, começa com calcários detríticos finos e puros, passando para calcários dolomitizados e calcários detríticos argilosos com intercalações de camadas de argila calcífera de reduzida espessura $(0,10 \mathrm{~m}$ a $0,25 \mathrm{~m})$. Esta seqüência se identifica com uma fase regressiva do mar após a transgressão gramame (Buerlen, 1959; Muniz, 1993). Aqui, os fósseis mostram as mesmas alterações rápidas que o caráter litológico. Há leitos estéreis e outros ricos em fósseis; há acumulações locais de conchas e leitos com abundância de fósseis em homogênea distribuição, sendo abundantes os moluscos e crustáceos.

White (1887) e Maury $(1924,1930)$ descreveram o maior número de fósseis dessa unidade. Os demais elementos fossilíferos desta formação foram descritos por Fernandes (1978, corais), Buge \& Muniz (1974, briozoários), Penna-Neme \& Muniz (1976, escafópodes), Oliveira (1953, nautilóides), Tinoco (1963, esclerodermitos de holoturóides e placas de equinóides), Muniz \& Ramirez (1977, icnofósseis), Tinoco (1977, foraminíferos) e Dolianiti (1955, vegetais). Os fósseis mais característicos da Formação Maria Farinha são os nautilóides Cimonia pernambucensis e Hercoglossa lamegoi, bem como o gastrópode Campanile buarquianus, e o crustáceo Callianassa.

A referida unidade litoestratigráfica é de idade paleocênica e representa um paleoambiente costeiro raso com variadas condições ecológicas, refletindo provavelmente movimentos oscilatórios da linha de costa (Beurlen, 1967). A idade atribuída foi baseada inicialmente em estudos geológicos e paleontológicos na localidade de Olinda, realizados por Oliveira \& Andrade Ramos (1956), onde foram levantadas detalhadas seções estratigráficas da formação, que foi então correlacionada ao Grupo Midway, da América do Norte, e Formação Soldado Rock de Trinidad, ambas de mesma idade, posteriormente confirmada por estudos subsequentes.

Os carbonatos da Formação Gramame estão sotopostos à Formação Maria Farinha, apresentando contato concordante. Segundo Feijó (1994), é interdigitada com a Formação Calumbi, e juntamente com as formações Gramame e Beberibe, a Formação Maria Farinha constitui um ciclo trangressivoregressivo, com transgressão acelerada, seguida de um relativo período estável e finalizado por uma demorada regressão (Gallo et al., 2001). 


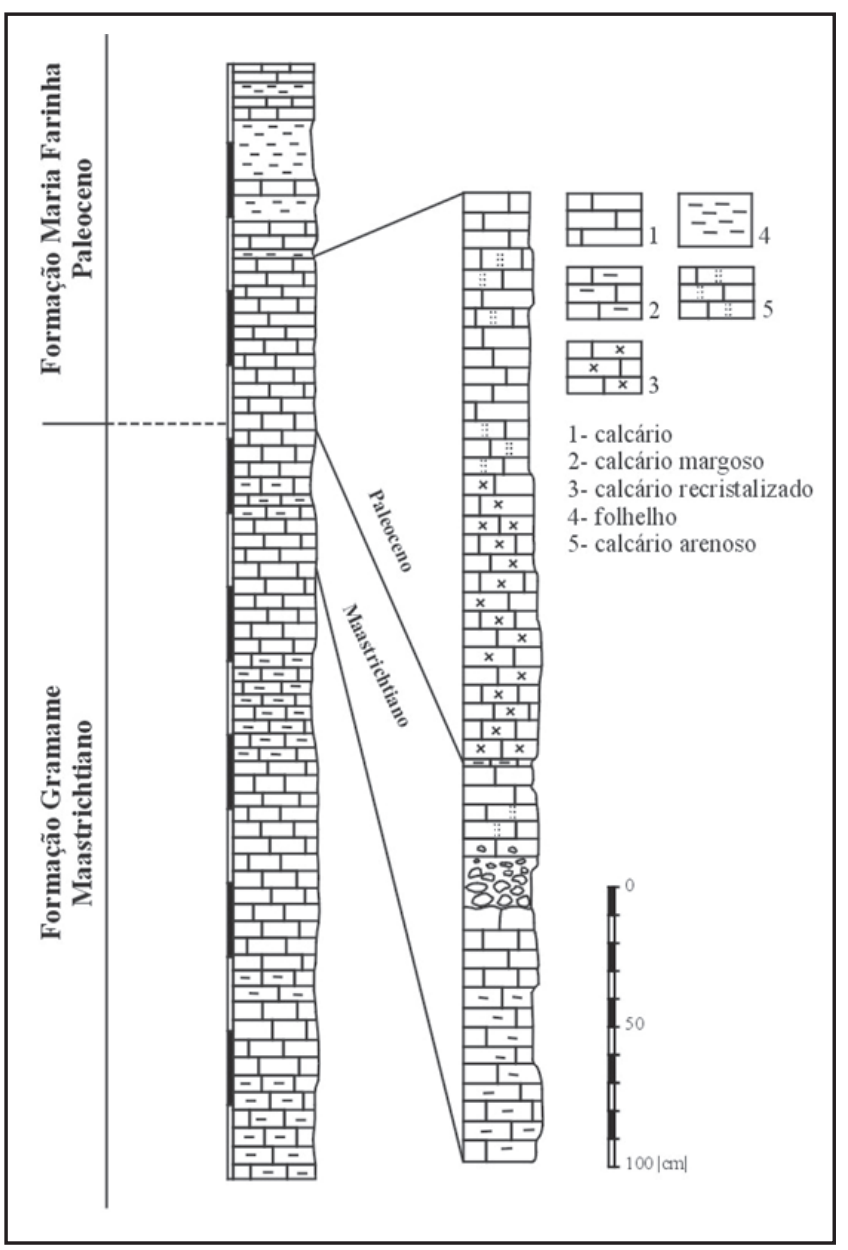

Figura 2. Coluna litoestratigráfica da pedreira Poty (modificado de Stinnesbeck \& Keller, 1996).

Figure 2. Lithostratigraphic column of the Poty Quarry (modified from Stinnesbeck \& Keller, 1996).

\section{Geologia Local}

As amostras de crustáceos decápodes estudadas foram coletadas na pedreira da fábrica de cimento Poty, município de Paulista, Estado de Pernambuco (Figura 1).

O perfil estudado possui aproximadamente $14 \mathrm{~m}$ de altura, sendo que os 9,5 m inferiores correspondem à Formação Gramame e o restante à Formação Maria Farinha (Figura 2). Tanto a Formação Gramame quanto a Formação Maria Farinha se caracterizam por uma alternância de calcários finamente estratificados, calcários margosos e margas calcárias, intensamente bioturbados. O conteúdo carbonático dos sedimentos varia gradualmente e as unidades litológicas são separadas por superfícies de erosão (Stinnesbeck \& Keller, 1996).

O conteúdo fossilífero das duas unidades litoestratigráficas na seção estudada é bem diferenciado. Enquanto nos sedimentos Gramame ocorrem cefalópodes amonóides, na Formação Maria Farinha estes elementos são substituídos pelos nautilóides. Além disso, os bivalves e gastrópodes perfazem faunas distintas, tipicamente paleocênicas, no pacote Maria Farinha (Beurlen, 1967).
O desaparecimento brusco e completo dos elementos cretácicos da Formação Gramame, bem como a mudança gradual de litologia, de calcário margoso para calcário puro detrítico, que reflete provavelmente uma rápida regressão do mar, reaparecendo uma fácies litorânea, são feições que indubitavelmente permitem separar as duas unidades litoestratigráficas ao longo do perfil, muito embora elas exibam uma transição gradativa.

\section{SISTEMÁTICA PALEONTOLÓGICA}

A nomenclatura morfológica e os termos aplicados nas descrições sistemáticas seguem a proposta de Brooks et al. (1969) e Feldmann \& Martins- Neto (1995).

Ordem DECAPODA Latreille, 1803

Infraordem BRACHYURA Latreille, 1803

Seção OXYSTOMATA Milne-Edwards, 1834

Superfamília CALAPPOIDEA de Haan, 1833

Família CALAPPIDAE de Haan, 1833

Subfamília CALAPPINAE de Haan, 1833

Gênero Necrocarcinus Bell, 1863

\section{Necrocarcinus sp.}

Figura 3

Material. MN-7992-I, um espécimen fragmentado.

Procedência. Pedreira Poty, município de Paulista, Pernambuco, Formação Maria Farinha (Figura 2); 8 ${ }^{\circ}$ 'S , 34 ${ }^{0} 53^{\prime} \mathrm{W}$.

Descrição. Carapaça pequena, achatada transversalmente e mais larga do que comprida, com sulcos transversais pouco marcados e coberta uniformemente por tubérculos de igual tamanho, cuja maior concentração está na região mediana, e também nas regiões branquial (alinhados longitudinalmente), gástrica e hepática (alinhados no sentido transversal). Regiões dorsais com limites pouco distintos. Mar-

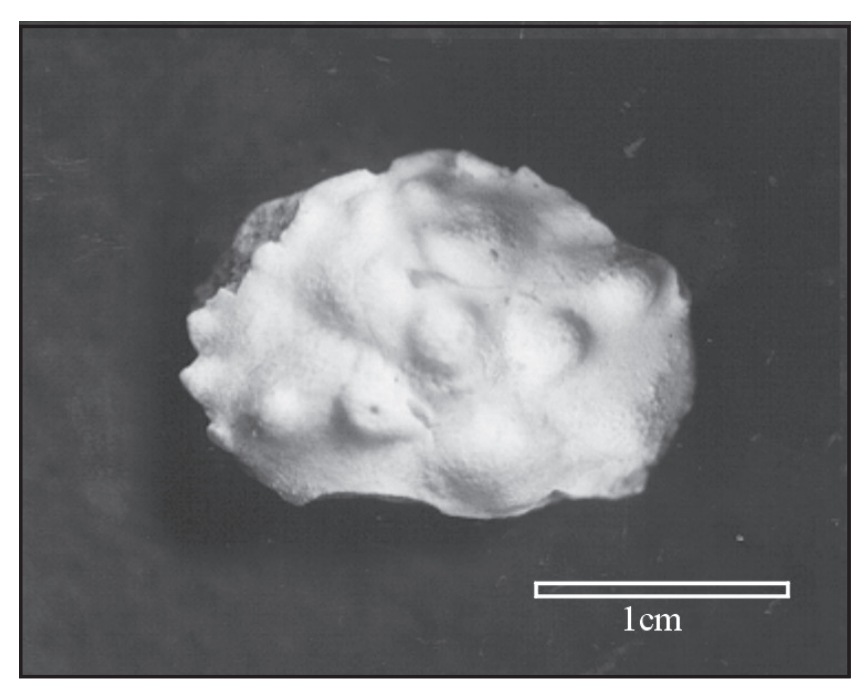

Figura 3. Necrocarcinus sp. Fragmento do tórax exibindo a morfologia típica do gênero.

Figure 3. Necrocarcinus sp. Thorax fragment showing the typical morphology of the genus. 
gem orbital estreita, direcionada anterolateralmente. Região hepática contendo três espinhos triangulares, subiguais, pouco pontiagudos, direcionados anterolateralmente. Margem póstero-lateral fracamente convexa, encurvada. Espinhos póstero-laterais direcionados para a frente. Fissuras das margens laterais amplas, vistas na metade anterior. Sulco cervical e cardíaco relativamente amplos. Regiões mesobranquial e epibranquial sem limites distintos entre si, formando um triângulo equiilátero. Região mesogástrica alongada, paralela à margem anterior, estreita anteriormente, alargando-se até a metade de sua extensão e estreitando-se posteriormente até atingir a largura inicial; contém dois tubérculos de igual tamanho, alinhados verticalmente. Região cardíaca intumescida, ovalada e com limites indistintos. O exemplar mede $15 \mathrm{~mm}$ de comprimento e $11 \mathrm{~mm}$ de largura.

Observações. O caráter fragmentário de MN-7992-I impediu sua designação específica.

Seção THORACOTREMATA Guinot, 1977 Superfamília OCYPODOIDEA Rafiresque, 1815 Família RETROPLUMIDAE Gill, 1894 Gênero Costacopluma Collins \& Morris, 1975

Costacopluma nordestina Feldmann \& Martins-Neto, 1995 Figuras 4-7

Material. MN-7993-I até 8043-I; 51 espécimens pouco fragmentados.

Procedência. Pedreira Poty, município de Paulista, Pernambuco, Formação Maria Farinha (Figura 2); 86' S, 34 $53^{\circ}$ W.

Descrição. Carapaça pequena, sub-retangular, mais larga do que longa. Margem orbital extensa, reta, direcionada para a margem anterior e levemente para a região antero-lateral, com pequenos espinhos. Rostro estreito, quase retangular, paralelo à margem anterior. Margem anterior da carapaça reta. Margem posterior também retilínea, menor do que a margem anterior. Margem ântero-lateral levemente encurvada, com dois espinhos curtos e agudos, direcionados para a frente. Margem póstero-lateral encurvada, de tamanho equivalente ao da margem posterior. Superfície da carapaça ornamentada por pústulas, costelas elevadas e protuberâncias. Costela transversal mais anterior estreita, sinuosa, arredondada. Duas protuberâncias contíguas, proeminentes, em forma de vaso na região metagástrica. Costelas epibranquiais estreitas lateral e axialmente, ocorrendo desde a interseção das margens laterais e ântero-laterais até a porção posterior da região urogástrica, alargando-se e ficando mais altas na área central da carapaça. Região metagástrica inflada, afunilada anteriormente, direcionada para frente, alargando-se abruptamente no nível da região epibranquial, onde se localiza uma protuberância. Região epibranquial, subtriangular, levemente intumescida com limites anteriores indistintos. Região mesobranquial convergente em direção ao centro, alongada, limitada por sulcos amplos e distintos que a separam das regiões metabranquial e epibranquial. Região urogástrica pequena, estreita, lisa, com limites posteriores indistintos. Região metabranquial ovalada,

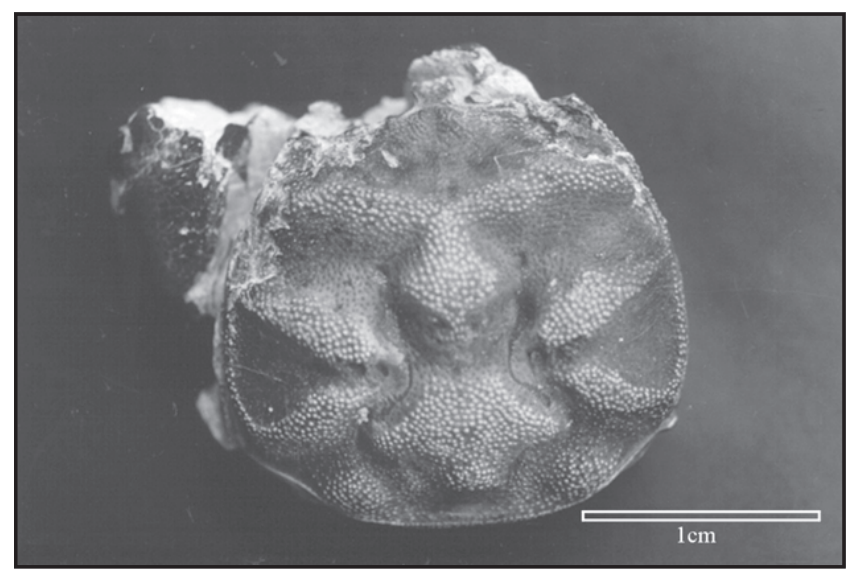

Figura 4. Costacopluma nordestina Feldmann \& Martins-Neto, 1995. Tórax exibindo a ornamentação típica da espécie.

Figure 4. Costacopluma nordestina Feldmann \& Martins-Neto, 1995. Thorax showing the typical ornamentation of the species.

levemente intumescida, paralela à margem posterior, anteriormente estreita e direcionada para o rostro, alargando-se lateralmente de forma gradual no nível da interseção entre as regiões meta e mesobranquial, onde a partir deste ponto, estreitase até atingir o comprimento original no nível da região metabranquial. Região cardíaca ampla, intumescida, paralela à margem anterior, no nível da região metabranquial e mesobranquial. Esterno subretangular. Esternitos torácicos distintos e similares. Esternitos de 1-4 fundidos em forma subtrapezoidal, paralelos à margem posterior do tórax. Quinto esternito subretangular, maior em comprimento do que o restante. Sexto esternito subtrapezoidal, intumescido, levemente mais estreito e longo que os demais. Margem ântero-lateral recurvada para margem anterior. Margem posterior reta. Margem pósterolateral levemente recurvada. Abdômen triangular, pontiagudo, recuado em relação ao esterno. Primeiro somito abdominal alongado transversalmente. Segundo somito retangular, ligeiramente mais longo que os outros, terceiro e quarto somitos levemente recurvados com concavidade voltada para margem anterior, levemente intumescida. Telso triangular com vértice anterior pouco distinto, mais curto que o quarto somito, base reta, quelípode agudo. Quelípode direito mais robusto que o esquerdo. Dáctilo móvel esquerdo levemente encurvado. Quelípode direito com os dois dáctilos encurvados para dentro, formando um gancho. Dedo fixo esquerdo triangular. Dáctilo agudo, forte, curvado para baixo. Coxa estreita, alongada. Própode liso, inflado, longo, dorso-ventralmente achatado, com fissuras. Mero longo, inflado, superfície superior retangular, com fissuras transversais e ornamentado nas bordas com punctas. Carpo encurtado, achatado transversalmente. Ísquio sub-retangular, alongado ântero-lateralmente. Base comprimida, reta. $\mathrm{Na}$ área dorsal, carapaça ornamentada por punctas que se concentram sobre as regiões descritas, não sendo vistas, porém, nos sulcos que limitam tais regiões. Ocorrem aglutinadas como microesférulas com arredondamento não uniforme nas margens da carapaça, desenhando uma borda inteiriça. Seu arranjo espacial se dá em função do formato da região que sobrepõem. $\mathrm{Na}$ região ventral, ocorrem em cada segmento do esterno e abdômen, paralelas à região anterior, alinhadas segundo a orientação 
dos segmentos que sobrepõem. Os exemplares possuem em média $18 \mathrm{~mm}$ de comprimento e $12 \mathrm{~mm}$ de largura.

\section{TAFONOMIA}

Os crustáceos decápodes da Formação Maria Farinha estão preservados tridimensionalmente em calcários finos detríticos, sob a forma de restos alterados por substituição, com cerca de $11 \%$ de espécimens articulados. Na maior parte do material amostrado (85\%), os espécimens estão relativamente fragmentados. $\mathrm{O}$ restante parece ter sofrido algum tipo de ação erosiva ou antrópica. O tamanho dos indivíduos é aproximadamente semelhante para todos, sugerindo que os mesmos sofreram morte seletiva.

Com base nas feições preservadas, foi possível tecer algumas considerações tafonômicas. Cabe ressaltar que o exame petrográfico, tanto dos fósseis quanto das rochas que os contêm, forneceria mais dados para a interpretação tafonômica. Contudo, esta pesquisa se detém nas feições macroscópicas como elementos para se traçar, preliminarmente, a trama tafonômica dos crustáceos decápodes estudados.

As feições macroscópicas empregadas na descrição da concentração fossilífera são importantes também na identificação de diferentes processos físico-químicos e biológicos responsáveis pela sua origem. Tais feições podem ser agrupadas em diversas categorias.

\section{Feições sedimentológicas}

As feições sedimentológicas são obtidas a partir da análise dos diferentes atributos bioestratinômicos e da distribuição e arranjo tridimensional dos bioclastos na matriz sedimentar (Holz \& Simões, 2002).

O grau de empacotamento observado no calcário margoso e sua relação com os crustáceos decápodes é do tipo dispersa (Kidwell \& Holland, 1991), onde os bioclastos, caoticamente orientados, são suportados pela matriz, estando esparsamente

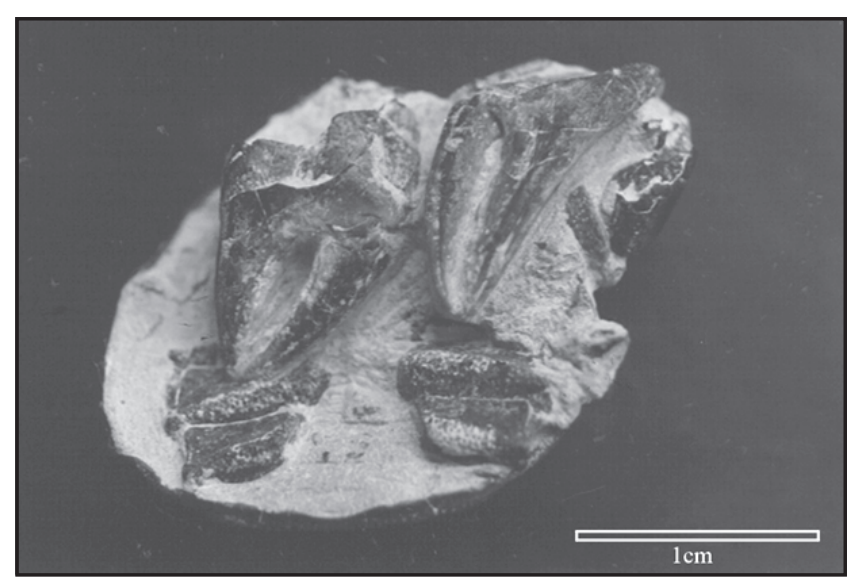

Figura 5. Costacopluma nordestina Feldmann \& Martins-Neto, 1995. Dáctilo (dedo móvel), dedo fixo e fragmentos dos esternitos abdominais.

Figure 5. Costacopluma nordestina Feldmann \& Martins- Neto, 1995. Dactylus (movable finger), fixed finger and fragments of the abdominal sternites. distribuídos. No aspecto grau de seleção, a concentração fossilífera é bem selecionada, pois cerca de $80 \%$ dos bioclastos exibem pequena variação nas classes de tamanho, ocupando duas classes ontogenéticas. Estes bioclastos apresentam-se com seu eixo maior alinhado paralela a subparalelamente em relação ao plano de acamamento (concordantes). Estas feições indicam baixo grau de retrabalhamento, acentuada seleção hidráulica e redeposição de fragmentos bioclásticos, não colocados em suspensão (Simões \& Holz, 2000).

\section{Feições estratigráficas}

Estas feições correspondem aos termos descritivos de tafocenoses em escala estratigráfica, envolvendo os aspectos dos restos fossilíferos dentro das camadas sedimentares (Holz \& Simões, 2002).

A concentração fossilífera ocorre em uma camada com estrutura interna simples, não exibindo variação vertical ou lateral das feições bioestratinômicas, sedimentológicas e paleoecológicas. Este aspecto pode indicar que esta concentração fossilífera foi gerada a partir de um único evento (Holz \& Simões, 2002).

\section{Feições bioestratinômicas}

Morte e necrólise. A tafocenose apresenta dominantemente elementos adultos (95\%), o que sugere morte seletiva para os elementos da concentração fossilífera analisada. $\mathrm{Na}$ associação de braquiúres, $11 \%$ apresenta vestígios de que foram soterrados ainda vivos. Neste caso, a luta pela vida preservada no registro fossilífero evidencia alta taxa de sedimentação durante o evento de soterramento. O processo de necrólise deve ter sido aeróbio, tendo em vista a ocorrência localizada de cristalização na parte superior de algumas carcaças, mais precisamente na região contígua ao tórax (Holz \& Simões, 2002).

Desarticulação. Dos 52 espécimens observados, a maioria (85\%) apresenta-se como formas desarticuladas (tórax). São reconhecidos ainda exemplares preservados como quelípodes articulados com o tórax, quelípodes articulados com o tórax e esterno, além de raros dátilos isolados.

Fragmentação, abrasão e bioerosão. Os espécimens desarticulados apresentam-se relativamente fragmentados em sua maioria (85\%). Não foram verificadas feições de abrasão, bioerosão ou incrustação dos bioclastos, indicando pequena exposição do esqueleto na interface água-sedimento, que sugere rápido soterramento por evento de alta taxa de sedimentação.

Transporte. Para avaliar seguramente o grau de transporte sofrido pelos elementos da tafocenose, foram observadas as feições de desarticulação, fragmentação, abrasão e bioerosão citadas acima. De acordo com estas feições, pode-se dizer que os bioclastos não apresentam evidências de transporte de longa distância. As formas preservadas com os apêndices ainda articulados sugerem que este transporte foi muito pequeno ou até mesmo nulo, pois esta forma de preservação sugere que os indivíduos foram surpreendidos pelo soterramento. Aliado a isso, têm-se as evidências de morte seletiva, que sugerem significativa seleção hidráulica em ambiente de alta energia. 


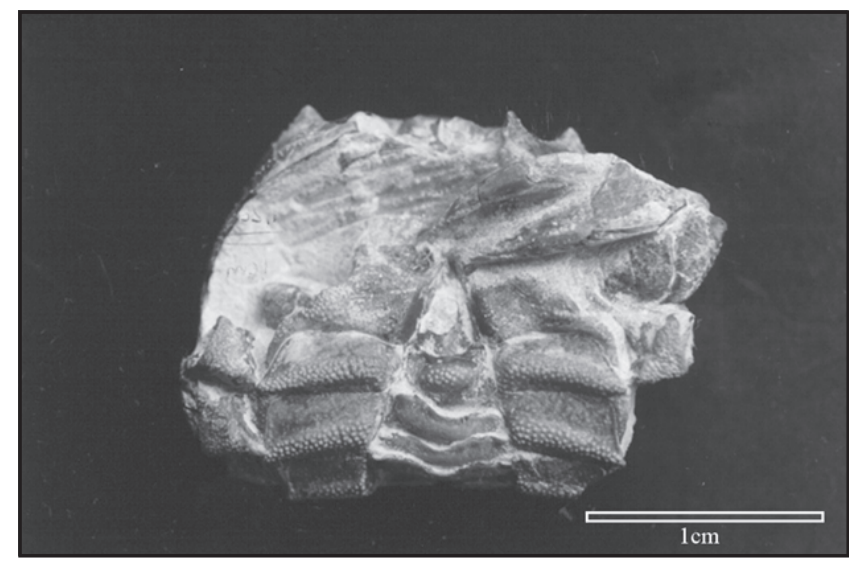

Figura 6. Costacopluma nordestina Feldmann \& Martins-Neto, 1995. Esternitos, somitos abdominais e telso.

Figure 6. Costacopluma nordestina Feldmann \& Martins-Neto, 1995. Sternites, abdominal somites and thelso.

As elevadas porcentagens de desarticulação e fragmentação indicam fraturamento mecânico por ondas em águas muito rasas, sugerindo, assim, elevada energia no ambiente deposicional durante o evento de soterramento.

Posição geral e condições de soterramento (modelo de Bishop, 1986). Dos 52 exemplares analisados, observou-se que apenas $11 \%$ estão preservados em posição de escape (Figura 8) e 89\% em posição normal. É importante ressaltar que em todos os especimens onde ocorrem tórax, não há evidência de dilatação e quebra. A alta porcentagem de indivíduos em posição normal sugere que a maioria dos braquiúres foi soterrada depois da morte, ainda que $11 \%$ deles represente indivíduos que foram surpreendidos pelo soterramento (apêndices articulados e voltados para cima). Por outro lado, o fato dos cadáveres estarem com o tórax intacto sugere que os processos de decomposição foram interrompidos com o soterramento.

\section{Feições paleoecológicas}

A composição taxonômica da concentração fossilífera estudada é monotípica e poliespecífica, por conter um único tipo de esqueleto, em duas diferentes espécies de crustáceos decápodes, Necrocarcinus sp. e Costacopluma nordestina Feldmann \& Martins-Neto. Cabe ressaltar aqui que concentrações monotípicas apresentam grande valor tafonômico ou paleoecológico, por refletir, na maioria das vezes, mortandade em massa, alto estresse ambiental, de intensa seleção hidrodinâmica ou preservação diferencial (Holz \& Simões, 2002).

\section{Implicações paleoambientais}

As feições sedimentológicas, estatigráficas e tafonômicas reconhecidas nos crustáceos decápodes e na rocha que os contêm permitiram supor que a concentração fossilífera em análise é parautóctone (Kidwell \& Bosence, 1991), tendo sido gerada por ondas de tempestade, a partir de um único evento. A boa e tridimensional preservação dos bioclastos e sua disposição caótica e concordante em

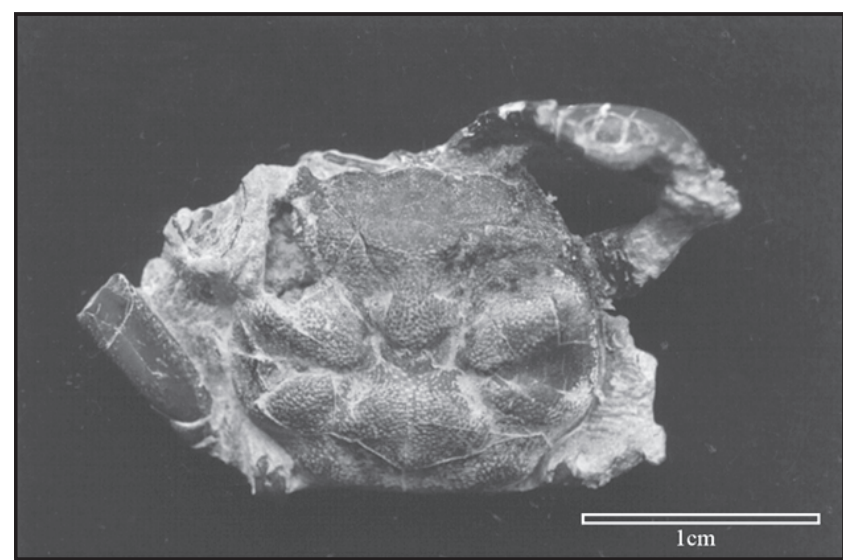

Figura 7. Costacopluma nordestina Feldmann \& Martins-Neto, 1995. Posição de escape.

Figure 7. Costacopluma nordestina Feldmann \& Martins-Neto, 1995. Scape position.

relação à matriz, juntamente com as feições que indicam baixo grau de retrabalhamento e acentuada seleção hidrodinâmica, comprovam esta hipótese. As feições paleoecológicas também são coerentes com esta interpretação. $\mathrm{O}$ caráter monotípico da concentração fossilífera, os tórax intactos, sem evidências de dilatação e quebra, e as formas preservadas com os apêndices articulados e voltados para cima podem refletir mortandade em massa.

As feições preservacionais, aliadas às evidências de acentuada seleção hidráulica e de morte seletiva, indicam elevada energia no ambiente deposicional durante o evento de soterramento. As altas porcentagens de desarticulação e fragmentação indicam fraturamento mecânico em águas muito rasas. Segundo Beurlen (1959), os fósseis da Formação Maria Farinha atestam ambiente costeiro; aliados aos dados geológicos, sugerem que tenha sofrido oscilações do nível do mar. Esta caracterização de ambiente deposicional é corroborada pelos crustáceos decápodes aqui estudados, correspondentes aos atuais goneplacídeos e ocipodídeos, típicos de ambientes costeiros.

As oscilações do nível do mar definem intercalações entre períodos mais agitados, que fragmentavam os restos dos organismos já mortos, com períodos mais calmos, onde os restos eram acumulados, depositados e sepultados.

As feições sedimentológicas, estratigráficas, bioestratinômicas e paleoecológicas sugerem, então, que a concentração fossilífera foi gerada por ondas de tempestade num momento em que o ambiente passava de um período mais calmo para outro mais agitado, surpreendendo alguns indivíduos da biocenose, representados aqui pelos braquiúres em posição de escape.

\section{AGRADECIMENTOS}

Os autores expressam seus agradecimentos à Valéria Gallo e Maria Somália Sales Viana pelo empréstimo dos materiais, bem como aos revisores e editores da RBP pelas valiosas contribuições. 


\section{REFERÊNCIAS BIBLIOGRÁFICAS}

Albertão, G.A.; Koutsoukos, E.A.M.; Regali, M.P.S.; Attrep Jr.; M. \& Martins Jr., P.P. 1993. The Cretaceous-Tertiary boundary (KTB) at Pernambuco/Paraíba basin, Northeastern Brazil. Acta Geologica Leopoldensia, 16 (38): 59-71.

Albertão, G.A.; Regali, M.P.S.; Koutsoukos, E.A.M. \& Martins Jr., P.P. 1994. O registro micropaleontológico, com base em foraminíferos e palinomorfos, no limite Cretáceo-Terciario (K$\mathrm{T})$, bacia de Pernambuco-Paraiba (PE/PB), Nordeste do Brasil - Inferências paleoambientais. Acta Geologica Leopoldensia, 39 (1): 131-145.

Bell, T. 1863. A monograph of the fossil malacostracous Crustacea of Great Britain. Pt. I, Crustacea of the London clay. Paleontograph Society of London, $44 \mathrm{p}$.

Buerlen, K. 1959. Observações sobre a Formação Maria Farinha, Estado de Pernambuco. Arquivos de Geologia, Escola de Geologia, Universidade do Recife, 1: 5-15.

Beurlen, K. 1967. Paleontologia da faixa costeira Recife-João Pessoa. Boletim da Sociedade Brasileira de Geologia, 16 (1): 73-79.

Bishop, G.A. 1986. Taphonomy of the north american decapods. Journal of Crustacean Biology, 6 (3): 326-355.

Brooks, H.K.; Carpenter, F.M.; Glaessner, M.F.; Hahn, G.; Huffman, R.L.; Holthuis, L.B.; Manning, R.B.; Manton, S.M.; McCormick, L.; Moore, R.C.; Newmann, W.A.; Palmer, A.R.; Rolfe, W.D.I.; Tasch, P.; Winter, T.H. \& Zullo, V.A. 1969. Arthropoda 4. In: R.C. Moore (ed.) Treatise on Invertebrate Paleontology, $1^{\mathrm{a}} \mathrm{ed}$., Lawrence, The Geological Society of America and The University of Kansas Press, v. 2, 651 p.

Buge, E. \& Muniz, G.C.B. 1974. Lunulites (Heteractis) barbosae, nouvelle spéce de bryozoaire lunulitiforme (Bryozoa, Cheilostomata) du Paléocène du Nord. Est. Du Brésil. Annales Paléontologie (Invertebrés), 60 (2): 191-202.

Collins, J.S.H. \& Moris, S.F. 1975. A new crab Costacopluma concava from the Upper Cretaceous of Nigeria. Palaeontology, 18: 823- 829 .

Dolianiti, E. 1955. Frutos de Nipa no Paleoceno de Pernambuco, Brasil. Rio de Janeiro, Departamento Nacional da Produção Mineral, Divisão de Geologia e Mineralogia, 36p. (Boletim 158).

Feijó, F.J. 1994. Bacia de Pernambuco-Paraíba. Boletim de Geociências da PETROBRÁS, 8 (1): 235-245.

Feldmann, R.M. \& Martins-Neto, R.G.1995. Costacopluma nordestina n. sp. (Decapoda:Retroplumidae) from the Maria Farinha formation (Paleocene) of Brazil. Journal of Paleontology, 69 (3): 610- 611.

Fernandes, A.C. S. 1978. Corais hermatípicos da Formação Maria Farinha, Paleoceno do Estado de Pernambuco. In: CONGRESSO BRASILEIRO DE GEOLOGIA, 30, 1978. Anais, Recife, SBG, v. 2, p. 960-964.

Gill, T. 1894. A new bassalian type of crabs. American Naturalist, 28:1043- 1045.

Gallo, V.; Figueiredo, F.J.; Carvalho, L.B. \& Azevedo, S.A.K. 2001. Vertebrate assemblage from the Maria Farinha Formation after the K-T boundary. News Jahrbuch Fur Geologieb and Palaeontologie Abhandlunger, 219: 261-284.

Guinot, D. 1977. Propositions pour une nouvelle classification des crustacés décapodes brachyoures. Compte Rendu Académie des Science de Paris, D (285):1049- 1052.

Haan, W. 1833- 1850. Crustacea. In: P.F. Siebold (ed.) Fauna japonica sive descriptio animalium quae in itinere per Japoniam, jussu et auspiciis superiorum qui summum in India Batava imperium tenent, suscepto, annis 1823-1830 collegit, notis, observationibus et odumbrationibus illustrativ, Arnz, p.1- 243.
Holz, M. \& Simões, M.G. 2002. Elementos fundamentais de Tafonomia. $1^{\text {a }}$ ed., Porto Alegre, EDUFRGS, 231 p.

Kidwell, S.M. \& Bosence, D.W.J. 1991. Taphonomy and timeaveraging of marine shelly faunas. In: P.A. Allison \& D.E. Briggs (eds.) Taphonomy releasing the data locked in the fossil record. Topics in Geobiology, New York, Plenum Press, p.115209.

Kidwell, S.M. \& Holland, S.M. 1991. Field description of coarse bioclastics fabrics. Palaios, 6: 426- 434.

Latreille, P.A. 1802- 1803. Histoire naturelle, générale et particulière des crustacés et des insectes, v. 3, F, Dufart, Paris, $468 \mathrm{p}$.

Mabesoone, J.M.; Tinoco, I.M. \& Coutinho, P.N. 1968. The Mesosoic-Tertiary boundary in Northeastern Brazil. Palaeogeography, Palaeoclimatology, Palaeoecology, 4: 161-185.

Maury, C.J. 1924. Fósseis Terciários do Brasil. Serviço Geológico e Mineralógico do Brasil, Monografia 4, p. 460-468.

Maury, C.J. 1930. O Cretáceo da Parahyba do Norte. Serviço Geológico e Mineralógico do Brasil, Monografia 8, 1-350.

Milne-Edwards, H. 1834. Histoire naturelle des crustacés, comprenant l'anatomie, la physiologie et la classification de ces animaux, Paris, v. 2, 532 p.

Muniz, G.C.B. 1993. Novos moluscos da Formação Gramame, Cretáceo Superior dos Estados da Paraíba e de Pernambuco, Nordeste do Brasil. Departamento de Geologia, Centro Tecnológico, Universidade Federal de Pernambuco, 1: 1202.

Muniz, G.C.B. \& Ramirez, L.V.O. 1977. Observações ichnológicas preliminares na Formação Maria Farinha, Paleoceno do Nordeste. In: SIMPÓSIO DE GEOLOGIA DO NORDESTE, 8, 1977. Atas, Campina Grande, SBG/NE, p. 111-119.

Oliveira, P.E. 1953. Invertebrados fósseis da Formação Maria Farinha. I- Cephalopoda. Rio de Janeiro, Departamento Nacional da Produção Mineral, Boletim da Divisão de Geologia e Mineralogia, 33 p. (Boletim 146).

Oliveira, P.E. \& Andrade Ramos, J.R. de. 1956. Geologia das Quadrículas de Recife e Pontas de Pedra. Rio de Janeiro, Departamento Nacional da Produção Mineral, Boletim da Divisão de Geologia e Mineralogia, Departamento Nacional de Produção Mineral, 60 p. (Boletim 151).

Penna-Neme, L. \& Muniz, G.C. B. 1976. Um novo Dentalium (Mollusca-Scaphopoda) da Formação Maria Farinha, Paleoceno de Pernambuco. Anais da Academia Brasileira de Ciências, 48 (3):523-525.

Rafinesque, C.S. 1815. Analyse de la Nature ou tableau de l'Univers et dês corps organises. Palermo, $224 \mathrm{p}$.

Simões, M.G. \& Holz, M. 2000. Tafonomia: processos e ambientes de fossilização. In: I.S. Carvalho (ed.) Paleontologia, Editora Interciência, Rio de Janeiro, p.19- 45.

Stinnesbeck, W. \& Keller, G. 1996. Environmental changes across the Cretaceous-Tertiary boundary in northeastern Brazil. In: G. Keller \& N. MacLeod (eds.) Cretaceous-Tertiary mass Extinction: Biotic and Environmental Changes, p. 451-469.

Távora, V.A. 2000. Carcinólitos da Formação Pirabas (Eomioceno), estado do Pará. Programa de Pós-Graduação em Geologia, Universidade Federal do Rio de Janeiro. Tese de Doutorado, $114 \mathrm{p}$.

Távora, V.A. 2001. Sobre a validade de Uca maracoani antiqua Brito, 1972 na Formação Pirabas, Estado do Pará. Revista Brasileira de Paleontologia, 2: 100.

Távora, V.A. \& Silva Junior, O.G. 2002. Petrografia e Geoquímica dos carcinólitos da ecofácies Baunilha Grande da Formação Pirabas (Eomioceno), Estado do Pará. Revista Brasileira de Paleontologia, 3: 5-16. 
Távora, V.A.; Mesquita, N.;Souza, S.R.; Cacela, A.S.M. \& Teixeira, S.G. 2002. Sistemática e tafonomia dos crustáceos decápodes da ecofácies Capanema da Formação Pirabas (Mioceno Inferior), Estado do Pará. Revista Brasileira de Geociências, 32 (2): 223230.

Tinoco, I.M. 1963. Fragmentos de equinodermas do Paleoceno de Pernambuco. Arquivos de Geologia, Escola de Geologia, Universidade do Recife, 4: 49-63.
Tinoco, I.M. 1977. Foraminíferos bentônicos da Formação Maria Farinha (Paleoceno de Pernambuco). In: SIMPÓSIO DE GEOLOGIA DO NORDESTE, 8, 1977. Atas, Campina Grande, SBG-Núcleo Nordeste, p. 65-69.

White, C. 1887. Contribuições à Paleontologia do Brasil. Archivos do Museu Nacional, 7: 1-273.

Received July, 2003; accepted January, 2004. 